\title{
The clinical relevance of necroinflammation-highlighting the importance of acute kidney injury and the adrenal glands
}

\author{
Wulf Tonnus ${ }^{1,3} \cdot$ Florian Gembardt $^{1} \cdot$ Markus Latk $^{1,3} \cdot$ Simon Parmentier ${ }^{1,3} \cdot$ Christian Hugo $^{1} \cdot$ Stefan R. Bornstein ${ }^{2}$. \\ Andreas Linkermann $\mathbb{D}^{1,3}$
}

Received: 17 April 2018 / Revised: 8 August 2018 / Accepted: 10 August 2018 / Published online: 17 September 2018

(c) ADMC Associazione Differenziamento e Morte Cellulare 2018

\begin{abstract}
Necroinflammation is defined as the inflammatory response to necrotic cell death. Different necrotic cell death pathways exhibit different immune reponses, despite a comparable level of intracellular content release (referred to as damage associated molecular patterns or DAMPs). In addition to DAMP release, which is inevitably associated with necrotic cell death, the active production of pro/anti-inflammatory cytokines characterizes certain necrotic pathways. Necroptosis, ferroptosis and pyroptosis, therefore, are immunogenic to a different extent. In this review, we discuss the clinical relevance of necroinflammation highlighting potential human serum markers. We focus on the role of the adrenal glands and the lungs as central organs affected by systemic and/or local DAMP release and underline their role in intensive care medicine. In addition, data from models of acute kidney injury (AKI) and kidney transplantation have significantly shaped the field of necroinflammation and may be helpful for the understanding of the potential role of dialysis and plasma exchange to treat ongoing necroinflammation upon intensive care unit (ICU) conditions. In conclusion, we are only beginning to understand the importance of necroinflammation in diseases and transplantation, including xenotransplantation. However, given the existing efforts to develop inhibitors of necrotic cell death (ferrostatins, necrostatins, etc), we consider it likely that interference with necroinflammation reaches clinical routine in the near future.
\end{abstract}

\section{Facts}

- Plasma membrane rupture causes the release of intracellular content, the immune response to which is referred to as necroinflammation

- Distinct modes of cell death are associated with specific patterns of necroinflammation

Edited by F. Pentimalli

Andreas Linkermann

andreas.linkermann@ukdd.de

1 Division of Nephrology, Department of Internal Medicine III, University Hospital Carl Gustav Carus at the Technische Universität Dresden, Dresden, Germany

2 Department of Internal Medicine III, University Hospital Carl Gustav Carus at the Technische Universität Dresden, Dresden, Germany

3 Biotechnology Center (BIOTEC), Technical University Dresden, Dresden, Germany
- Inhibition of Regulated Necrosis (RN), such as necroptosis, pyroptosis, ferroptosis, not only preserves cellular function, but also prevents necroinflammation

- Necroinflammation drives the pathophysiology of autoimmunity, ischemic injury, sepsis, acute respiratory distress syndrome (ARDS) and many other diseases

- Antibody-mediated rejection of solid organ allografts may be a consequence of necroinflammation

- The adrenal gland and the lungs are central organs affected by necroinflammation

\section{Open questions}

- How is necroinflammation detected in clinical routine?

- What is the relative contribution of different RN modes (necroptosis, pyroptosis, ferroptosis) to overall organ damage in distinct diseases?

- Which combination therapy of necrostatin, inflammasome inhibitors, ferrostatins, etc. best prevents necroinflammation in different setting? 
- How can the adrenal gland and the lungs be protected during systemic necroinflammation?

\section{Introduction to the immunogenicity of regulated cell death pathways}

Apoptosis, necroptosis and pyroptosis are tightly interconnected cell death pathways, all of which are mediated or prevented by caspase activation. In contrast to the peroxidation/autoxidation-controlled ferroptotic cell death system, we therefore refer to apoptosis, necroptosis and pyroptosis as the "caspase-controlled" cell death system (Fig. 1). Hardly anything is known about interconnections between these two major cell death modalities. Those pathways that result in necrosis (defined by the irreversible loss of plasma membrane integrity) release damage associated molecular patterns (DAMPs), which were recently classified into seven classes (Table 1) [1]. This is not the case during apoptosis which is not associated with plasma membrane rupture. For further details, we kindly refer the reader to a recently published comprehensive review on DAMPs [1].

\section{The caspase-controlled cell death system}

\section{Apoptosis}

With more than 10 billion cells dying by apoptosis each day, it represents the default pathway of regulated cell death (RCD) [2]. Unfortunately, RCD is still used synonymously with apoptosis. This nomenclature is clearly incorrect because signaling pathways of necrosis are regulated as well, and in fact regulate apoptosis signaling [3]. Caspases, the main mediators of apoptosis, also mediate pyroptosis $[4,5]$ (see below) and, in the case of caspase- 8 , inhibit necroptotic signaling $[6,7]$. This demonstrates the interconnectivity of apoptosis, necroptosis and pyroptosis. However, the caspase system has not been demonstrated to affect ferroptotic signaling that appears to be independent of the caspase system. Fig. 1 provides a simplified overview about the interconnectivity of these four RCD-pathways, categorized into the ferroptosis system and the caspase system. Importantly, apoptosis occurs in most all physiological conditions in which systemic inflammation as a consequence of cellular turnover would be disadvantageous. We therefore consider apoptosis the least immunogenic form of RCD.

\section{Necroptosis}

Our knowledge about the signaling pathway of necroptosis has recently been summarized in several excellent reviews in detail [3, 8-19]. Undoubtedly, the (pseudo)kinases in the necroptosis pathway (mixed lineage kinase domain like MLKL, RIPK1 and RIPK3) represent excellent therapeutic targets [20-22]. With the details of the necroptosis signaling cascade in mind, we like to emphasize that it still remains unclear how the plasma membrane loses its integrity during necroptosis. While phosphorylation of MLKL is required for necroptosis [23, 24], data are accumulating that it is not sufficient [25-27]. The only known kinase capable of phosphorylating MLKL is RIPK3 following oligomerization and assembly of the necrosome, a higher order structure the assembly of which is prevented by the RHIM domain of RIPK1 [28, 29]. Caspase- 8 controls necroptosis signaling and effectively prevents it, at least in mice that (unlike humans) do not express caspase-10. The role of caspase-10 in humans in this sense is incompletely investigated. However, the reversal of the lethal phenotype of caspase- 8 deficient mice on a RIPK3-[6, 7] or MLKL-deficient [30] background clearly demonstrates that necroptosis is part of the caspase-controlled cell death system (Fig. 1). In addition to caspases, however, polyubiquitination and other means of posttranslational modification regulate RIPK1-dependent necroptosis at least downstream of TNFR1 signalling. The details of RIPK1 polyubiquitin modifications by linear and/or K63 linkages are beyond the scope of this review and have been reviewed in detail elsewhere [13, 31, 32].

It has been reported that active production of cytokines occurs during necroptosis progression (see below), but the precise mechanisms are incompletely understood. However, prevention of necroptosis signaling by necrostatins should prevent the release of immune modifying cytokines, but it remains unclear if necrostatins affect $\mathrm{CD} 8+\mathrm{T}$ cell cross priming by dendritic cells [33].

\section{Pyroptosis}

The activation of inflammatory caspases (caspase- 1 and caspase-4/5 (caspase-11 in mice)) results in the cleavage of critical proinflammatory proteins and cell death by pyroptosis $[4,5,34,35]$. Maturation of pro-IL-1 $\beta$ and pro-IL18 to their active forms is mediated by caspase-mediated cleavage. In addition, the intracellular protein gasdermin D (GSDMD) is cleaved by caspase-11, thereby releasing the $\mathrm{N}$-terminal fragment (GSDMD-NT), which may oligomerize and form a membrane pore that may allow the release of IL-1 $\beta$ and IL-18 into the extracellular space [36]. It is unclear to which extent this pore formation may be transient or associated with the necrotic cell death of pyroptosis, but the GSDMD-NT fragment is absolutely required for pyroptosis execution $[37,38]$. It is beyond the scope of this review to list the upstream inflammasomal components that trigger pyroptosis in various scenarios, but it should be 


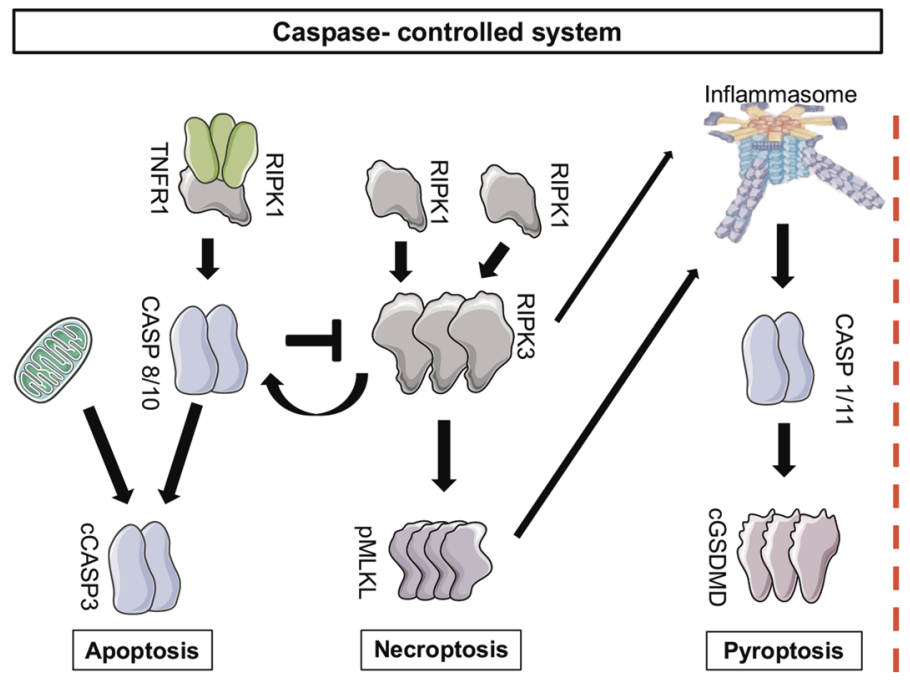

Peroxidase- controlled system

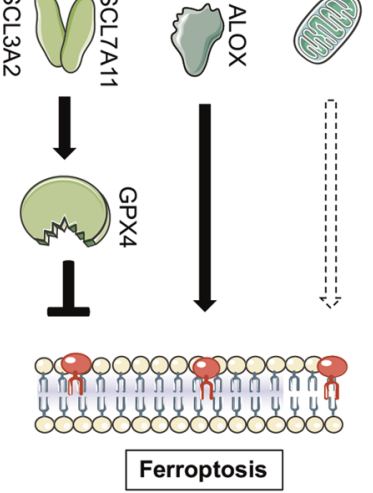

Fig. 1 An overview of the pathways of regulated cell death. In general, two systems may be best differentiated when regulated cell death is considered. The caspase-controlled system includes apoptosis, necroptosis and pyroptosis, and has been studied in great detail over the last decades. In contrast, the peroxidation-controlled system of ferroptotic cell death functions entirely independent of the caspasecontrolled network. Importantly, both systems contribute to human diseases. Targeting clinically relevant cell death, therefore, should at

least require a combination therapy of these two systems that may exhibit some redundant functions. Similarly, within the caspasecontrolled system, inhibition of either pathway may result in alternative pathways. With the idea of necroinflammation in mind, it may be helpful to shift a deadly signal from a highly immunogenic pathway (such as pyroptosis) towards a pathway with less immunogenic potency (such as apoptosis)

Table 1 Classification of DAMPs as drivers of necroinflammation-According to Sarhan et al. [1]

\begin{tabular}{|c|c|}
\hline Classes of DAMPs & Categories of cognate recognition receptors/sensors \\
\hline Class Ia DAMPs & $\begin{array}{l}\text { sensed via binding to "classical" recognition receptors ( }=\text { PRRs such as TLRs, RLRs) on/in innate immune cells such as } \\
\text { phagocytes incl. DCs, thereby triggering signaling pathways }\end{array}$ \\
\hline Class Ib DAMPs & $\begin{array}{l}\text { recognized by "non-classical" recognition receptors such as the scavenger receptor CD91 and the purinergic receptors } \mathrm{P} 2 \mathrm{X} 7 \\
\text { thereby contributing to phagocytes incl. DCs activation }\end{array}$ \\
\hline Class II DAMPs & sensed by NLRP3 receptor to form assembly of the NLRP3 inflammasome contributing to phagocytes incl. DC activation \\
\hline Class III DAMPs & recognized by the activating NKG2D receptor, e.g., on NK cells thereby contributing to NK cell activation \\
\hline Class IV DAMPs & $\begin{array}{l}\text { recognized by binding to pre-existing natural IgM antibodies to activate the complement cascade thereby contributing to } \\
\text { inflammation }\end{array}$ \\
\hline Class V DAMPs & $\begin{array}{l}\text { dyshomeostasis-associated molecular patterns (such as accumulation of unfolded proteins in the ER; intracellular ion } \\
\text { perturbations, hypoxia, redox imbalance; etc). sensed by sensors of the UPR (e.g., PERK) or sensed by NLRP3 receptor } \\
\text { thereby contributing to inflammation and DC activation. }\end{array}$ \\
\hline Class VI DAMPs & recognized by the "non-classical" recognition receptor GPR91 thereby promoting inflammation \\
\hline Class VII DAMPs & sensed by nociceptors such as TRPA1 channels and TRPV1 \\
\hline
\end{tabular}

$C D$ cluster of differentiation, $D A M P s$ damage-associated molecular patterns, $D C s$ dendritic cells, $I g M$ immunoglobulin $\mathrm{M}, N K$ natural killer, $N K G 2 D$ natural killer group 2 member D, NLRP3 NLR family, pyrin domain-containing protein $3, P E R K$ the protein kinase R (PKR)-like endoplasmic reticulum kinase, $P R R s$ pattern recognition receptors, $P 2 X 7$ purinergic receptor $\mathrm{P} 2 \mathrm{X} 7, R L R s$ retinoic acid-inducible gene (RIG)I-like receptors, TLR toll-like receptor, TRPA1 transient receptor potential cation channel subfamily A member 1 , TRPV1 transient receptor potential vanilloid subtype $1, U P R$ unfolded protein response

mentioned that caspase- 8 can result in similar maturation of proinflammatory cytokines upon genetic interference with caspase-1. Along these lines, it has been reported that RIPK3 [39-41] and MLKL [42] can function as upstream regulators of inflammasome assembly and pyroptosis signaling.This highlights why pyroptosis is a part of the caspase-controlled cell death system (Fig. 1).
In humans, the gasdermins are a family of at least six members: GSDMA, GSDMB, GSDMC, GSDMD, GSDME (also known as DFNA5 [43]) and DFNB59 (also referred to as pejvakin). Similar pore forming functions and involvement in necrotic cell death may be anticipated for the other members. Interestingly, caspase- 3 was demonstrated to be capable of inducing necrotic cell death through GSDME 
[43]. Activation of caspase-3, therefore, can no longer be considered to detect apoptotic cell death.

Due to its highly immunogenic nature, pyroptosis appears to be involved in a plethora of pathological settings (see below). This is highlighted by the clinical use of the recombinant human IL-1R antagonist anakinra and the antiIL-1 $\beta$-antibody canakimumab. However, with an increase in understanding of the upstream nature of the pyroptosis pathway, a therapeutic approach that targets inflammasomes directly should be favorable. Prevention of caspase activity specific for pyroptosis without interference with apoptosis (compare Fig. 1) may represent a useful approach to avoid proinflammatory cytokine maturation. In summary, pyroptosis may be considered the most proinflammatory and therefore the prototype of immunogenic cell death as the release of the long lasting, highly proinflammatory cytokines IL- $1 \beta$ and IL-18 is associated with this form of death.

\section{The lipid peroxidation/autoxation-controlled necrosis system}

\section{Ferroptosis}

In contrast to the caspase-controlled system, ferroptosis prototypically represents the peroxidation-controlled system (Fig. 1) of RCD [44]. Ferroptosis has been recently reviewed in detail [44]. Briefly, the system of ferroptosis was discovered by screening for lethal compounds that induced cell death in tumor cell lines. The small molecule erastin was demonstrated to be effective in killing RAStransformed cancer cells in vitro [45]. Mechanistically, Erastin inhibits system Xc, a cystin-glutamate antiporter, thereby reducing the source to generate intracellular glutathione (GSH), the loss of which was lethal to cells in an iron-dependent manner [46, 47]. GSH or other cysteinederived thiols were demonstrated to be required for the GSH peroxidase 4 (GPX4) to prevent ferroptosis and lipid peroxidation of defined phosphatidylethanolamine (PE) residues. Genetic depletion of GPX4 in renal tubules or kidney ischemic injury results in ferroptosis and acute kidney injury (AKI) in mice [48, 49]. Remarkably, GPX4 is a selenocysteine-containing protein, explaining the requirement for nutritional uptake of selenium for normal physiology, the deficiency of which results in epileptic seizures [50]. Specific poly-unsaturated fatty acids (PUFAs) are more prone to peroxidation than others. Recently, the lipoxygenase ALOX15 has been identified to regulate sensitivity towards lipid peroxidation during ferroptosis [48, 51, 52]. However, ALOX15 activation itself is not sufficient to "activate" membrane bound PUFAs to execute cell death, but requires to be transactivated upon binding to PEBP1 [53, 54]. New data, however, indicate that besides lipoxygenase (LOX)-mediated peroxidation,
LOX-independent autoxation may be more important for the death process itself $[55,56]$. This is crucial to distinguish when lipoxygenases are discussed as potential therapeutic targets. Despite these new insights, mechanisms of cell death execution and plasma membrane rupture downstream of lipid peroxidation remain unknown. However, cells undergoing ferroptosis deplete NADPH in a lipid peroxidation dependent manner $[57,58]$.

Therapeutically, several inhibitors of ferroptosis have been reported, such as ferrostatin-1, liproxstatin-1, 11-92 and 16-86 [21, 48, 59,60]) most of which prevent lipid peroxidation [61]. In contrast, ferroptosis inducers (FINs) have been separated in two classes of drugs. Type $1 \mathrm{FINs}$ function through the depletion of GSH (e.g., erastin) whereas type 2 FINs directly target the active center of GPX4 (e.g., RSL3 [62]). A novel mechanism was reported for $\mathrm{FINO}_{2}$, an endoperoxide-containing 1,2-dioxolane that indirectly inhibits GPX4 enzymatic function and directly oxidizes iron [63]. The newly described class 3 inducers, mainly FIN56 [64], work through depletion of CoQ10 and GPX4, instead of inhibiting GPX4 activity.

Regarding its immunogenicity, ferroptosis has been hardly investigated at all. Therefore, we do not have good reason to believe that ferroptosis modulates the immune system in either way unless data will be provided. Oxidized lipids, however, may be proinflammatory also during ferroptotic cell death through the establishment of neoepitopes. In the hierarchial model (Fig. 2), we currently rank ferroptosis less immunogenic than pyroptosis, but less antiinflammatory than necroptosis.

\section{Clinically relevant necroinflammation}

\section{Markers of systemic inflammation in humans}

White blood counts have been traditionally used as surrogate markers of inflammation in general, and despite the decades of clinical experience with this marker, the last 30 years have brought up a series of proinflammatory cytokines and acute phase proteins that are most commonly used in every day clinical routine. Some of these may be upregulated because of necroinflammation. In the following paragraphs, we revisit our knowledge about classical markers of inflammation and other pathophysiological instances as potentially useful tools for the assessment of necroinflammation.

C-reactive protein is an acute phase protein that is expressed predominantly upon IL-6/IL6R $\alpha$ STAT3 signaling in hepatocytes. IL-6 is less commonly measured directly because of its relatively short half life. However, with IL-6 representing a proinflammatory signal downstream in the NF-kB pathway, it is commonly 


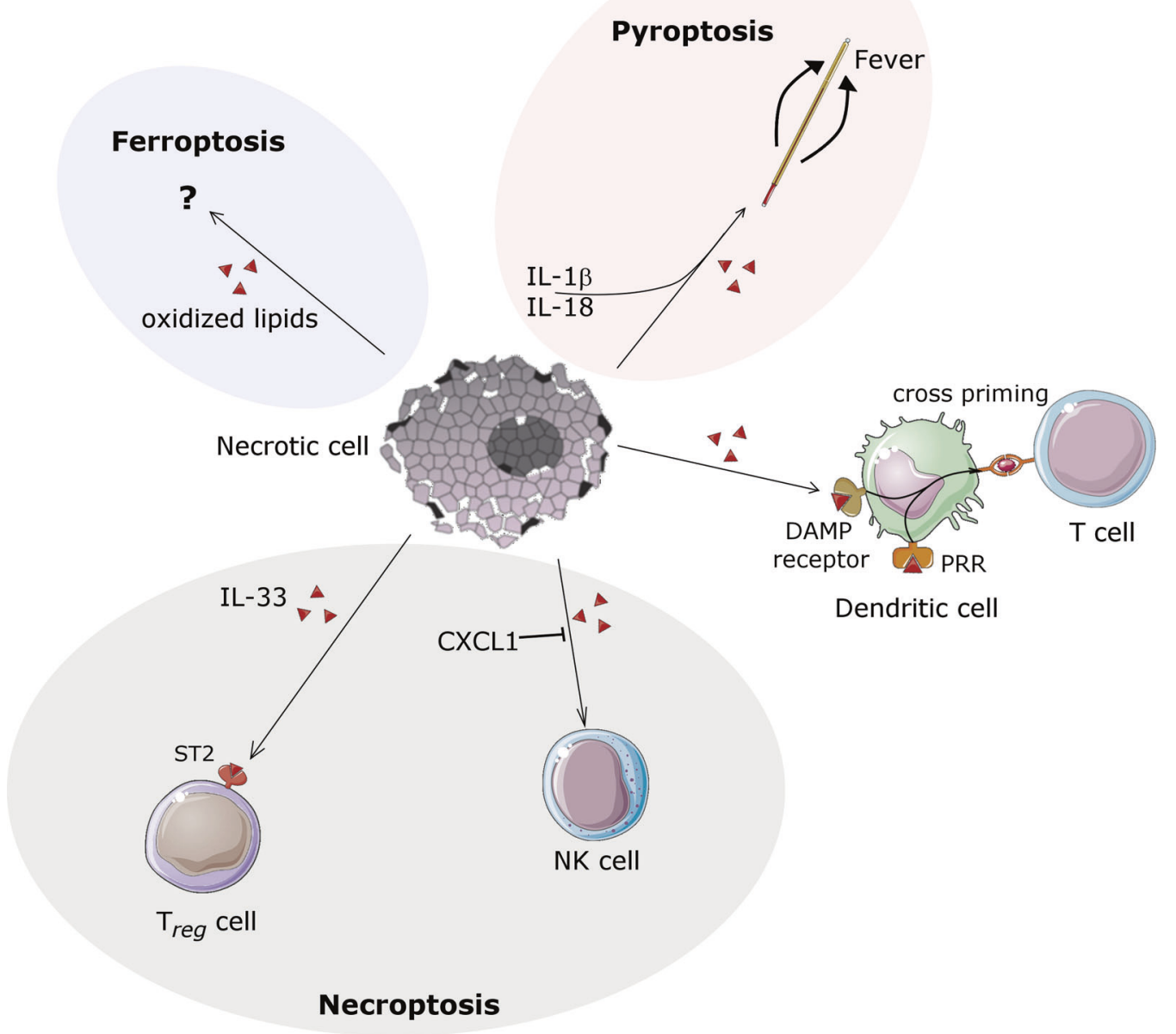

Fig. 2 Necroinflammation mediated by nonspecific DAMPs and additional specific factors-a hierarchical model. Necrotic cell death by definition results in plasma membrane rupture. This feature is common to all pathways of regulated necrosis (RN) and accidental necrosis. DAMPs and intracellular organelles are released during necrosis and the immune system may establish first contacts with these intracellular features. In addition, during the time necessary to undergo specific RN signals, certain RN-specific factors are activated. In this sense, during necroptosis, CXCL1 may inhibit infiltrating NK cells and IL-33 may signal to stabilize regulatory $\mathrm{T}$ cells through ST2

expressed downstream of TNFR1- and/or Toll-like (TLR) receptor signaling and might be actively produced during necroptosis depending on the cell culture or the tissue [65]. Because TNFR1 and TLR that signal through the RHIMdomain containing protein TRIF are default necroptosis receptors, IL-6 and CRP may be useful markers for necroinflammation, but certainly useful for TNF and TLRdriven diseases.

IL-1 $\beta$ and IL-18 can be easily determined in human sera, but at least in the case of IL-18 it would be overexaggerated to consider this cytokine a standard marker for inflammation. However, its relatively high specificity for pyroptosis/ receptors, respectively. In contrast to these anti-inflammatory components, pyroptosis is associated with the production/maturation and the gasdermin D-dependent release of IL-1b and IL-18, long lasting cytokines that increase the setpoint for body temperature and thereby induce fever. Hardly anything is known about the immunogenicity of ferroptotic cell death. Given these specific immunomodulatory features, necrosis does not always result in stereotype activation of the immune system. However, DAMP release per se is immunogenic and may be sufficient to induce dendritic cell cross priming. Importantly, DAMPs are not released during apoptosis gasdermin-mediated necrosis may change this view, at least when clinical trials are considered. In this respect, some brilliant studies have already looked at IL-18 in preclinical sepsis models [66] which are now translated to clinical trials. Along these lines, it is remarkable that GSDMD-deficient mice are resistant to LPS-induced lethal shock [67].

IL-33 and CXCL1 are not routinely measured to evaluate inflammatory responses in humans, and data about the therapeutic potential of either IL-33 interference or application of IL-33 as a therapeutically active recombinant protein are controversial. When IL-33 was first suggested as the "necroptotic DAMP" [68], distinction to pyroptosis 
signaling has not been taken into consideration. In the case of CXCL1, published as a selective necroptosis-mediated chemokine that might signal through the mincle ligand, consequences for necroinflammation may be hard to predict from the published data [69]. However, accumulating evidence strongly suggests that necroptosis has antiinflammatory properties [70] that may limit the DAMPinduced immune response to a local environment. This may at least be partially explained through IL-33-ST2 signalling that may stabilize Tregs in the microenvironment of tumors and/or the necroptotically dying cells [71]. Importantly, both pro- and anti-inflammatory properties have been reported for CXCL1, and it is not entirely clear how precisely CXCL1 functions in a post-sihemic scenario.

\section{Potassium}

Potassium is an important electrolyte, which is mostly located intracellularly. However, if cells loose membrane integrity, large amounts of intracellular potassium are released, promoting extracellular and thus systemic acidosis. Upon renal failure, hyperkalemia may cause detrimental cardiac arrhythmias. Rather than being a suitable marker for necroinflammation, serum potassium may be valuable as an additive non-specific damage marker in patients with chronic renal failure. Importantly, a potassium-dependent inward-rectifying current was interpreted as a priming signal for inflammasomes, but precise mechanisms remain unclear today [72]. This confirms a role of extracellular potassium in the context of regulated necrosis.

\section{Anti-nuclear antibodies (ANA) / ds-DNA}

ANAs are markers of a variety of autoimmune diseases. In contrast to anti-neutrophil cytoplasmic antibodies (ANCAs) (see below), they constitute an epiphenomenon and are not causative of the autoimmune disease. Double-stranded DNA-(dsDNA) autoantibodies have been described to be more specific, but both ANAs and dsDNA antibodies are recognized diagnostic criteria for systemic lupus erythemathosus (SLE). Other diseases associated with ANAs are Crohn's disease and rheumatoid/mixed-tissue diseases. Due to their frequent use in clinical routine, ANAs and dsDNA antibodies are a good example for the potential of biomarkers for necroinflammation. In theory, necrosis is the sole possible form of cell death that allows generation of autoantibodies with intracellular epitopes. Along similar lines, it was recently demonstrated that impaired efferocytosis (the phagocytic uptake of necrotic debris from tissues) by mononuclear cells results in autoimmunity in mice. As one example, the loss of the protein rubicon results in the dysfunction of LC3-associated phagocytosis (also referred to as non-canonical autophagy or LAP). Consequently, rubicon-deficient mice exhibit a lupus-like phenotype that is associated with ANAs and dsDNA antibody formation [73].

\section{Lactate dehydrogenase (LDH)}

Some infectious diseases of the lung, e.g., Pneumocystis jirovecii (former Pneumocystis carinii) infections typically are associated with an increase in serum lactate dehydrogenase levels [74]. This may well represent a form of necroinflammation as these fungi may be cleared from the infected lung cells by necrosis, although secondary necrosis following apoptotic clearing might as well result in $\mathrm{LDH}$ release. Therefore, sole measurement of $\mathrm{LDH}$ levels is not sufficient to detect necrosis. Whereas this may cause a specific signal, trauma and intoxications are also associated with increased serum LDH levels. However, in the latter cases, therapeutic intervention may be virtually impossible unless a continuous pathophysiological process underlies the increase of serum LDH levels.

\section{Specific clinical situations}

It is impossible to list all clinically important conditions that may involve necroinflammation. We subjectively selected those that appeared to be of outstanding importance in our point of view, some of which are discussed in the following paragraphs, others are listed in Table 2. Obviously, the investigation of necroinflammation requires future studies in the fields of basic research and clinical trials.

\section{Focus 1:Necroinflammation in the adrenal gland}

The clinical importance of cell death in the adrenal gland During shock, the systolic blood pressure drops below the heart rate (positive shock index). The blood pressure is controlled by several factors, including catecholamines, aldosterone, glucocorticoids and others. Epinephrine and norepinephrine, the major catecholamines for the maintainance of the blood pressure, are produced in the medulla of the adrenal gland (glandulasuprarenalis). Aldosteron and glucocorticoids are produced in the cortex (zona glomerulosa and zona fasciculata, respectively) [75].

Therefore, the adrenal gland is the epicenter of hormonemediated blood pressure regulation during sepsis and shock [76]. Necrotic damage in adrenal gland cells has dramatic consequences to all vital signs and is therefore most recognized not only by endocrinologists, but in intensive care medicine (see below). The capillary network within the adrenal gland is depicted in (Fig. 3). Importantly, the 
Table 2 Clinically relevant settings associated with necroinflammation ${ }^{\mathrm{a}}$

\begin{tabular}{|c|c|}
\hline Clinically relevant setting & Necroinflammatory response \\
\hline $\begin{array}{l}\text { Acute respiratory distress syndrome } \\
\text { (ARDS) }\end{array}$ & $\begin{array}{l}\text { Necrotic debris from any trauma, following the blood flow, accumulates in the pulmonary capillaries. } \\
\text { This may trigger necroinflammation, ferroptosis and necroptosis to result in ARDS [132-135]. }\end{array}$ \\
\hline Solid organ transplantation & $\begin{array}{l}\text { Necrotic debris derived from transplanted organs that contain necrotic parenchymal or endothelial cells } \\
\text { was demonstrated to induce necrotic cell death in the lungs }[88,136] \text {. }\end{array}$ \\
\hline Extracorporal circulation and dialysis & $\begin{array}{l}\text { Mechanical necrosis of blood cells occurs during extracorporal treatments such as dialysis, plasma } \\
\text { exchange, etc.. This may drive necroinflammation }[128,137] .\end{array}$ \\
\hline Trauma / surgery & $\begin{array}{l}\text { Trauma-associated, sterile inflammation represents a prototype model for necroinflammation [138- } \\
\text { 141]. }\end{array}$ \\
\hline Infections diseases, SIRS and Sepsis & $\begin{array}{l}\text { Several pathways of regulated necrosis contribute to the pathogenesis of SIRS and sepsis. This has } \\
\text { been demonstrated for necroptosis }[112,118,142-147] \text { and pyroptosis }[148-151] \text {. }\end{array}$ \\
\hline Intoxications & $\begin{array}{l}\text { Diverse necrosis-inducing toxins trigger necroinflammation [152-154], as first assessed in vivo } 100 \\
\text { years ago [155]. Data for an involvement of pyroptosis exist [156]. }\end{array}$ \\
\hline Ischemia & $\begin{array}{l}\text { Sterile inflammation following ischemic injury is at least partially driven by necrosis and DAMP } \\
\text { release [157-161]. }\end{array}$ \\
\hline
\end{tabular}

${ }^{\mathrm{a}}$ It is imporssible to mention all clinically relevant situations that involve necroinflammation. The given clinically relevant settings were selected on an entirely subjective opinion of the authors

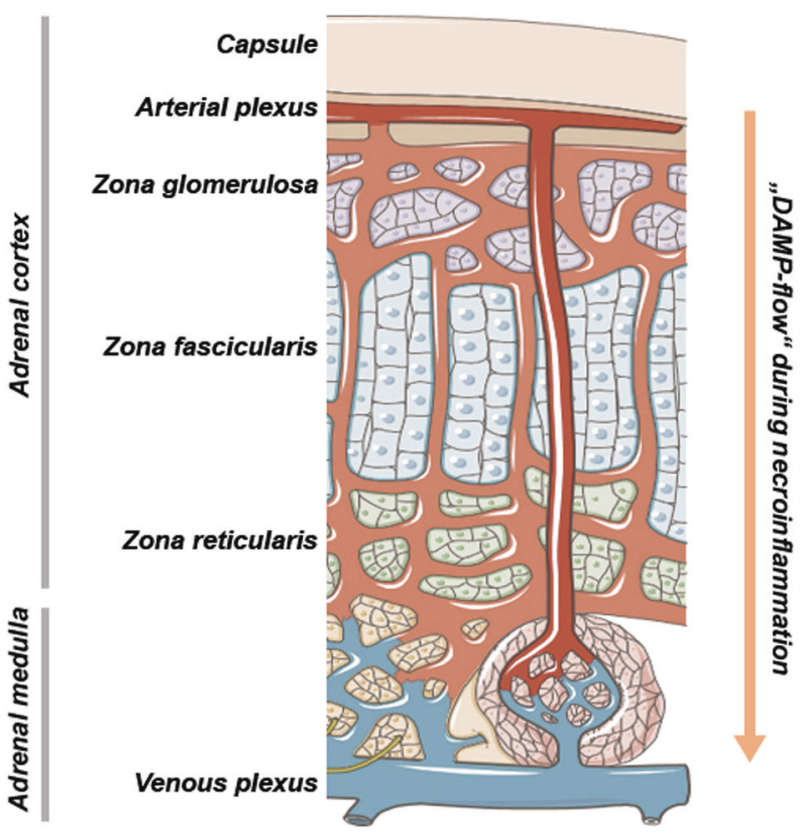

Fig. 3 Anatomic basis of necroinflammation in the adrenal glands. The adrenal gland blood flow is regulated in a highly controlled manner during physiological conditions and during adrenal stress, such as sepsis and the acute drop of blood pressure. Importantly, the adrenal medulla, the major production site of catecholamines that maintain blood pressure, is supplied by two different sources of areterial blood. A significant fraction of the arterial blood directly reaches the medulla without previous flowthrough of the cortical parenchymal compartment. During DAMP release from either distant organs or the cortical adrenal cells of the zona reticularis, fasciculata and glomerulosa, respectively, the adrenal medulla is the first site of contact, similar to the lungs in systemic vasculature. The adrenal gland, therefore, should be considered a major organ responsible for complications upon diseases that involve necroinflammation

adrenal medulla receives blood from two different sources. While sinusoids spanning the entire cortex confluent in the medullary plexus, medullary arteries from a subcapsular reservoir pass the cortex without branching to directly enter the adrenal medulla. DAMPs released from cortical adrenal gland cells, therefore, directly affect the medullary microenvironment without passing the capillary network in the lungs. In addition, circulating DAMPs that originate from damage in distant organs, also reach the adrenal medulla without previous dilution in the cortex. The adrenal gland may therefore be recognized as a primarily susceptible organ to affection by necroinflammation. Given the importance of the hormone producing cells for blood pressure regulation in the organism, dysfunction of such cells may have fatal consequences. We therefore decided to put the adrenal gland into the focus on this review on the clinical relevance of necroinflammation. This notion is additionally supported by the striking correlation between fatal murine sepsis and adrenal gland (necro-)inflammation [77]. In addition, cell death in the adrenal is of clinical importance during the development of adrenal insufficiency [78] and during aging (adrenopause).

Currently, data available on cell death in the adrenal gland are limited and the most reliable publications date back to the days before regulated necrosis was described [79]. Whereas it is clear that TLRs are involved in an adequate response of the adrenal gland to stress [80], the role of TRIF and other RHIM-domain containing proteins, and the entire signaling pathway of necroptosis have not been investigated. Some data suggested apoptosis to occur during sepsis, but these conclusions were based on TUNEL positivity and not on the direct in situ detection of cleaved caspases or even caspase activity. Recent data from adrenal tumors suggested at least a partial role for apoptosis and caspase activation was reported to be controlled by the 
BIRC7 system [81]. A role for p53 was suggested also in adrenocortical carcinomas [82], but ferroptosis has not been discussed. Adrenal cell derived cell lines are also limited. H295T, a human adrenocortical carcinoma cell line, has been analyzed without great detail. In summary, data on cell death and necroinflammation are limited, but given the clinical importance of this system during intensive care conditions, we predict that novel data on the role of regulated necrosis pathways will significantly forward this field and advice to focus on the adrenal gland if necroinflammation is planned to be investigated. Joining forces of endocrinologists and cell death researchers to unravel the mechanisms of necrosis in the adrenal glands will allow directing protective agents (necrostatins, ferrostatins) to these well-perfused organs with potentially great benefit for critically ill patients.

\section{Focus 2: AKI and its therapy}

Accumulating data generated from in vivo and ex vivo models of AKI have contributed to our understanding of necroinflammation in vivo, rendering the kidney probably the best investigated organ for necroinflammation [83, 84]. Distant organ effects following AKI have first been described by the group of Hamid Rabb [85-87]. Later, these data obtained from AKI have been confirmed during kidney transplantation models [88], and the need to prevent regulated necrosis in AKI was widely recognized [89]. In recent years, the importance of synchronized regulated necrosis mediated by ferroptosis in renal tubular cell death has been discovered [49]. Given the strong necroinflammatory potency of the kidney and the dominance of ferroptosis over other $\mathrm{RN}$ pathways [48, 59] in the renal tissue, the necroinflammatory nature of ferroptosis may be best estimated from these models.

Interference with RN and associated necroinflammation has been investigated employing inhibitors of necroptosis [90] and ferroptosis [49, 91]. The third generation ferrostatin 16-86 still remains the strongest single compound for the prevention of AKI induced by ischemia-reperfusion injury [49]. However, in the case of folic acid induced nephropathy, the data are less clear. While it was first believed that necroptosis was of minor importance in this setting [92], both ferroptosis and necroptosis, depending on the timing of the interference, may be important [93]. This may reflect the independent features of regulated necrosis as a primary damage and a second wave of renal failure associated with immune cell infiltration (necroinflammation) [93].

Another example of AKI associated necroinflammation is ANCA-associated vasculitis. In this disease, endothelial cells undergo unknown necrotic damage following the release of neutrophil extracellular traps (NETs), the release of which depends on MLKL and is sensitive to necrostatins treatment in mice and humans [94]. Disease progression classically involves systemic inflammation markers (such as CRP and others [95]) and severe fatigue, suggesting a necroinflammatory component in this disorder.

Extracorporal circulation and dialysis Extracorporal circulation such as hemodialysis, hemodiafiltration, plasma exchange and extracorporal membrane oxygenation ([96]) are known to be associated with increased levels of inflammatory markers [97, 98]. The origin of this inflammation has been anecdotally associated with contact of blood cells with the surface of the filters used during extracorporal circulation, which were therefore referred to as "biocompatible" and were speculated to have been promoted the postdialysis fatigue [99]. Some features of these methods, however, may be better explained by necroinflammation. If such cells are mechanically damaged to release DAMPs, however, therapeutic interference with a defined cell death pathway would become impossible.

Connection to any extracorporal circulation device also affects the intravasal volume, explaining hypotension as a frequent clinical problem. On the basis of this low intravasal volume, additional factors, such as myocardial infarction, vascular leakage syndromes (such as severe inflammatory response syndrome (SIRS) or sepsis, could be detrimental. In the case of low blood pressure on ICUs, continuous veno-venous hemofiltration may be used instead of classical hemodialysis to maintain filtration upon low blood pressure, but such systems require anticoagulation, e.g., with citrate. Higher citrate concentrations affect the blood $\mathrm{pH}$ levels and thereby indirectly influence the serum potassium concentration. Obviously, this affects pyroptosis and limits the use of serum postassium as a damage marker. Potassium, however, follows a high filtration coefficient which allows to relatively easily maintain the serum potassium concentration.

\section{Focus 3: Intensive care medicine-Necrosis on the ICU}

Inflammation following trauma and acute respiratory distress syndrome (ARDS) ARDS is a consequence of severe trauma, and a classical example of necroinflammation as the pathophysiological basis of disease [100]. Pyroptosis and necroptosis, and the entire caspase-controlled cell death system may be involved in the pathogenesis. Along these lines, especially the death of alveolar macrophages may drive the disease [101]. However, inflammatory processes during major trauma and ARDS are by no means limited to necroinflammation, but also include activation of NF-kB and other proinflammatory signatures that are likely to be independent of necrosis [102]. Therefore, given the lack of specific markers for necroinflammation, it is difficult 
to differentiate the source of inflammation in these complex patients. Pathophysiologically, ARDS is thought to be mediated by DAMPs that are released from the default traumatic region, as long as the draining veins follow the bood stream into the lung capillaries (referred to as remote organ injury [103]). Clinically, ARDS is characterized by pulmonary (alveolar) edema resulting in compromised gas exchange and systemic hypoxia. High pressure mechanical ventilation is often required, possibly resulting in even more cellular damage if dosed unappropriately. Neutrophils are centrally involved in the pathogenesis [104], potentially releasing NETs and possibly undergoing NETosis. Some reports suggested that NET release, as necroptosis, depends on RIPK3 and pMLKL [94, 105]. Remarkbly, ARDS is treated with high-dose steroids. Indeed, two studies found glucocorticoids to reduce time at respiratory devices in sepsis patients significantly [106, 107]. Interpreted in the light of necroinflammation, these trials underline the need to break through the necroinflammatory circuit in acute lung injury.

Infectious diseases The best explanation for the evolutionary conservation of several distinct signaling pathways of regulated necrosis and RCD is based on the assumption that microbes prevent apoptosis signaling and are therefore cleared by alternative necrotic pathways $[6,18,108-111]$. Therefore, microbes might be less effectively cleared upon therapeutic RN-blockade. We therefore demand caution when therapeutic interference with necroptosis and other $\mathrm{RN}$-pathways is considered. So far, however, this concern has not translated into a clinical problem in phase I and phase II trials for necroptosis inhibitors / RIP1 kinase inhibitors. Some weak necroptosis inhibitors, such as phenytoin [112], have been applied to patients on a daily basis for decades without a significant increase in the risk of infectious diseases. Indeed, this may imply that chronic diseases (e.g., neurodegenerative disorders [113, 114]) should also be treated with RN-Inhibitors. It is not the intention of this review to refer to all bacteria, viruses, parasites and fungi that control and/or hijack RN patwhays, but excellent reviews on these topics exist. With respect to the adrenal, however, the Waterhouse-Friedrichsen syndrome causes acute adrenal insufficiency and severe bleeding within the adrenal gland upon infection with meningococci [115] and other bacteria. It is associated with high mortality and its pathophysiology remains entirely elusive.

Ischemia-reperfusion injury (IRI) In several clinical settings, necrosis is a consequence of IRI. Whereas ferroptosis appears to be the dominant cell death pathway in stroke, kidney and liver [44, 48, 49, 59, 116, 117], necroptosis was demonstrated to be of importance in the myocardial tissue
[118]. However, the role of ferroptosis has not been looked at in detail in myocardial tissue upon ischemic challenge. Oversimplification, however, will not solve tissue specificities and inter-organ variations that are characteristic of IRI-induced regulated necrosis. Indeed, it is of outstanding importance to characterize the relative contribution of necroptosis, pyroptosis and ferroptosis, and potentially other cell death pathways [3], in each of the specific ischemic conditions.

In ST elevation myocardial infarction, recanalization of coronary arteries is followed by IRI to the cardiomyocytes. In this scenario, interference with necroptosis by application of a necrostatin via the cardiac cathether appears easily possible. Of course, the primary intention of such a procedure is to preseve the function of the cardiomyocytes. However, the sterile immune response to the necrotic tissue named post-myocardial infarction syndrome, or "Dressler's syndrome", may involve severe inflammation and pericarditis [119]. Clearly, this rare pathophysiology involves necroinflammation, but remains elusive why some patients develop this condition whereas others with a similar load of necrotic debris do not.

Other acute diseases and clinical conditions involve IRI, such as resuscitation (IRI of the entire organism), therapeutic lysis of thromboembolism, and potentially IRI occurs upon the growth of solid cancers. In theory, these conditions exhibit potentially important therapeutic targets to prevent necroinflammation.

Toxicities Drug overdosage and intoxications are common on ICUs and often involve necrotic injury, only few of which can be effectively treated with plasma exchange [120]. Commonly affected tissues include, but are not limited to liver, heart, lungs, kidneys and bone marrow. In a variety of preclinical experiments, the liver has been demonstrated to undergo necroptotic cell death [121], but controversial findings exist [122]. In particular models of toxic AKI (e.g., folic acid induced AKI), at least two waves of cell death appear to drive the pathophysiology. In this sense, a role for Fn14 and TWEAK has been noticed for a long time [123], but was connected to necroptosis-driven necroinflammation only recently [93]. In addition, some chemotherapeutic drugs may induce different cell death modalities in different concentrations. In this sense, sorafenib can induce both necroptosis and ferroptosis, and therefore differentially induce necroinflammation, upon cancer treatment [124].

\section{Focus 4: Transplantation medicine}

Solid organ transplantation During the process of solid organ transplantation, hypoxia may cause necrosis (in particular ferroptosis and necroptosis [125-127]). Upon 
contact with the transplant, naïve B cells of the recipient are thought to be primed by necrotic parenchymal and endothelial cells. Upon tapering of the immunosuppressive regimen used in each specific setting, and in the context of bacterial or viral infection, antibody-mediated rejection (ABMR) of the graft may result years after the transplantation process [128]. Additionally, necroptotic cells have been demonstrated to exhibit strong $\mathrm{T}$ cell cross priming properties [33]. Consequentely, therapeutic addition of necrostatins and/or ferrostatins to the cold storage solution during organ perfusion may represent a promising therapeutic approach for the prevention of ABMR, especially in the so-called marginal organs [129].

Xenotransplantation In addition to conventional solid organ transplantation, the broad use of xenotransplantation may well be limited by necroinflammation. It is beyond the scope of this review to list all independent features of rejection of a xenotransplant, but prevention of necroptosis and ferroptosis appear to represent interesting approaches to limit xenogenic immune responses. Additionally, following the focus on the adrenal gland, xenotransplantation for the treatment of adrenal insufficiency emerges [78]. This appears to be possible through the transplantation of bovine adrenal cells, encapsulated in alginate. This particular material allows diffusion of adrenal hormones whereas immune cells cannot enter this artificial tissue, and the xenotransplanted adrenal cells thus cannot be rejected [130]. Recent data suggest that this approach is not limited to single cell types [130] but may be employed to generate a bioartificial adrenal cortex [131]. However, it is currently unclear to which extent alginate may prevent the necroinflammatory stimulus to enter the systemic vasculature.

\section{Conclusions and outlook}

The most important unanswered questions with respect to the novel concept of necroinflammation are summarized in Box 1. In general, targeting necroinflammation rather than regulated necrosis (necroptosis, pyroptosis, ferroptosis) may be more applicable in clinical routine because the therapeutic window to interfere with RN may be too narrow and the cell death mode too hard to diagnose quickly enough to apply RN-inhibitors. However, due to the lack of specific markers of necroinflammation, the unknown systemic origin of necroinflammation and overlapping and interconnected RN and immune cell pathways, successful therapeutic strategies may be decades away. However, understanding necroinflammation as a disease-causing condition is a major step towards translational medicine and the generation of cell death therapeutics.
Box 1: Open questions regarding the concept of necroinflammation Does necroinflammation contribute to the pathogenesis of autoimmunity?

Autoimmunity may develop as a consequence of necrotic cell death (based on the concept of necroinflammation), but may be predisposed by dysfunction of the removal of necrotic debris [73, 162]. This may explain the generation of autoantibodies (e.g., anti dsDNA antibodies, ANAs) in patients that suffer from SLE. It is, however, unclear why necrotic debris should accumulate in mice that have functional apoptotic signaling and do not suffer from obvious viral or bacterial infections. Clinically, it is tempting to speculate that a flare in a patient with autoimmunity is triggered by necrosis (e.g., necroptosis or pyroptosis) because viral and bacterial infections are known triggers of autoimmunity, classically preceeding the disease activity by $1-2$ weeks.

What determines the intensity of a necroinflammatory response? It may be to simple to hypothesize that a large number of necrotic cells drive a more pronounced necroinflammatory response. At least with respect to myocardial infarction or stroke, it remains unclear why some patients suffer from inflammation following necrotic injury (e.g., Dressler's syndrome, see above) whereas others do not. Why might necroptosis be less immunogenic than pyroptosis/ gasdermin-mediated necrosis?

During necroptosis, some reports indicated active maturation of IL-33 [68] and CXCL1 [69]. These factors are widely believed to limit an immune reponse by "stabilizing" regulatory $\mathrm{T}$ cells and inhibiting infiltrating NK cells, respectively. In contrast, long lasting cytokines such as IL-1 $\beta$ and IL-18, that are actively matured and released during gasdermin-mediated necrosis, may increase the setpoint for body temperature in the hypothalamus to induce fever, may stimulate acute phase proteins in the liver and are more likely to contribute to the development of a SIRS. Inhibition of pyroptosis, therefore, may be a promising therapeutic approach for SIRS patients.

How to best detect necroinflammation?

In contrast to direct detection of necroptosis in tissues (e.g., by a pMLKL or a pRIPK3 antibody [25, 112], or by staining for ACSL4 as an indicator for ferroptosis sensitivity [163]), or potentially by a cleavage specific GSDMD-antibody, no marker for necroinflammation has been established so far. Whereas high serum levels of IL18 and IL-1 $\beta$ detection may point towards pyroptosis-induced necroinflammation, the detection of IL-33 and CXCL1 may be more specific for necroptosis as an underlying cause. Non-specific markers, such as LDH, troponin I or troponin T, NGAL, TIM-1 (also referred to as KIM-1) are useful to determine the source of necroinflammation, but not the cell death mode. Only the detection of the precise cell death mode would allow pharmacological inhibition and successful targeting of necroinflammation.

Acknowledgements Work in the Linkermann Lab is funded by the Medical Clinic 3, University Hospital Carl Gustav Carus Dresden, Germany, and supported by the SFB-TRR205, SFB-TRR 127 and the international research training group (IRTG) 2251. AL is supported by a Heisenberg-Professorship granted by the German Research Foundation (DFG). FG is funded by a grant from the DFG (GE 2845/1-1). We like to thank all members of the Linkermann Lab for continuous discussions on the topic of necroinflammation.

\section{Compliance with ethical standards}

Conflict of interest The authors declare that they have no conflict of interest. 


\section{References}

1. Sarhan M, Land WG, Tonnus W, Hugo CP, Linkermann A. Origin and consequences of necroinflammation. Physiol Rev. 2018;98:727-80.

2. Nagata S. Apoptosis and clearance of apoptotic cells. Annu Rev Immunol. 2018;36:489-517.

3. Galluzzi L, Vitale I, Aaronson SA, Abrams JM, Adam D, Agostinis P, et al. Molecular mechanisms of cell death: recommendations of the Nomenclature Committee on Cell Death 2018. Cell death Differ. 2018;25:486-541.

4. Bergsbaken T, Fink SL, Cookson BT. Pyroptosis: host cell death and inflammation. NatRevMicrobiol. 2009;7:99-109.

5. Vande Walle L, Lamkanfi M. Pyroptosis. Curr Biol. 2016;26: R568-572.

6. Kaiser WJ, Upton JW, Long AB, Livingston-Rosanoff D, DaleyBauer LP, Hakem R, et al. RIP3 mediates the embryonic lethality of caspase-8-deficient mice. Nature. 2011;471:368-72.

7. Oberst A, Dillon CP, Weinlich R, McCormick LL, Fitzgerald P, Pop C, et al. Catalytic activity of the caspase-8-FLIP(L) complex inhibits RIPK3-dependent necrosis. Nature. 2011;471:363-7.

8. Ch'en IL, Tsau JS, Molkentin JD, Komatsu M, Hedrick SM. Mechanisms of necroptosis in $\mathrm{T}$ cells. J Exp Med. 2011;208:633-41.

9. Chan FK, Luz NF, Moriwaki K. Programmed necrosis in the cross talk of cell death and inflammation. Annu Rev Immunol. 2015;33:79-106.

10. Christofferson DE, Yuan J. Necroptosis as an alternative form of programmed cell death. Curr Opin Cell Biol. 2010;22:263-8.

11. de Almagro MC, Goncharov T, Newton K, Vucic D. Cellular IAP proteins and LUBAC differentially regulate necrosomeassociated RIP1 ubiquitination. Cell Death Dis. 2015;6:e1800.

12. Declercq W, Vanden Berghe T, Vandenabeele P. RIP kinases at the crossroads of cell death and survival. Cell. 2009;138:229-32.

13. Dondelinger Y, Darding M, Bertrand MJ, Walczak H. Polyubiquitination in TNFR1-mediated necroptosis. Cell Mol Life Sci. 2016;73:2165-76.

14. Linkermann A, Green DR. Necroptosis. New Engl J Med. 2014;370:455-65.

15. Ofengeim D, Yuan J. Regulation of RIP1 kinase signalling at the crossroads of inflammation and cell death. Nat Rev Mol Cell Biol. 2013;14:727-36.

16. Pasparakis M, Vandenabeele P. Necroptosis and its role in inflammation. Nature. 2015;517:311-20.

17. Silke J, Rickard JA, Gerlic M. The diverse role of RIP kinases in necroptosis and inflammation. Nat Immunol. 2015;16:689-97.

18. Upton JW, Kaiser WJ, Mocarski ES. Virus inhibition of RIP3dependent necrosis. Cell Host Microbe. 2010;7:302-13.

19. Zhou W, Yuan J. Necroptosis in health and diseases. Semin Dev Biol. 2014;35:14-23.

20. Conrad M, Angeli JP, Vandenabeele P, Stockwell BR. Regulated necrosis: disease relevance and therapeutic opportunities. Nat Rev Drug Discov. 2016;15:348-66.

21. Degterev A, Linkermann A. Generation of small molecules to interfere with regulated necrosis. Cell Mol Life Sci. 2016;73:2251-67.

22. Li Y, Qian L, Yuan J. Small molecule probes for cellular death machines. Curr Opin Chem Biol. 2017;39:74-82.

23. Sun L, Wang H, Wang Z, He S, Chen S, Liao D, et al. Mixed lineage kinase domain-like protein mediates necrosis signaling downstream of RIP3 kinase. Cell. 2012;148:213-27.

24. Zhao J, Jitkaew S, Cai Z, Choksi S, Li Q, Luo J, et al. Mixed lineage kinase domain-like is a key receptor interacting protein 3 downstream component of TNF-induced necrosis. Proc Natl Acad Sci USA. 2012;109:5322-7.
25. Gong Y-N, Guy C, Olauson H, Becker JU, Yang M, Fitzgerald $\mathrm{P}$, et al. ESCRT-III acts downstream of MLKL to regulate necroptotic cell death and its consequences. Cell. 2017;169:286-300.e216.

26. Yoon S, Kovalenko A, Bogdanov K, Wallach D. MLKL, the protein that mediates necroptosis, also regulates endosomal trafficking and extracellular vesicle generation. Immunity. 2017;47:51-65.e57.

27. Zargarian S, Shlomovitz I, Erlich Z, Hourizadeh A, Ofir-Birin Y, Croker BA, et al. Phosphatidylserine externalization, "necroptotic bodies" release, and phagocytosis during necroptosis. PLoS Biol. 2017;15:e2002711.

28. Lin J, Kumari S, Kim C, Van TM, Wachsmuth L, Polykratis A, et al. RIPK1 counteracts ZBP1-mediated necroptosis to inhibit inflammation. Nature. 2016;540:124-8.

29. Newton K, Wickliffe KE, Maltzman A, Dugger DL, Strasser A, Pham VC, et al. RIPK1 inhibits ZBP1-driven necroptosis during development. Nature. 2016;540:129-33.

30. Alvarez-Diaz S, Dillon CP, Lalaoui N, Tanzer MC, Rodriguez DA, Lin A, et al. The pseudokinase MLKL and the kinase RIPK 3 have distinct roles in autoimmune disease caused by loss of death-receptor-induced apoptosis. Immunity 2016;45: 513-526.

31. Rieser E, Cordier SM, Walczak H. Linear ubiquitination: a newly discovered regulator of cell signalling. Trends Biochem. 2013;38:94-102.

32. Walczak H. TNF and ubiquitin at the crossroads of gene activation, cell death, inflammation, and cancer. ImmunolRev. 2011;244:9-28.

33. Yatim N, Jusforgues-Saklani H, Orozco S, Schulz O, Barreira da Silva R, Reis e Sousa C, et al. RIPK1 and NF-kappaB signaling in dying cells determines cross-priming of CD8(+) T cells. Sci (New Y, NY). 2015;350:328-34.

34. Fink SL, Cookson BT. Pyroptosis and host cell death responses during salmonella infection. Cell Microbiol. 2007;9:2562-70.

35. Schroder K, Tschopp J. The inflammasomes. Cell. 2010;140:821-32.

36. Ding J, Wang K, Liu W, She Y, Sun Q, Shi J, et al. Pore-forming activity and structural autoinhibition of the gasdermin family. Nature. 2016;535:111-6.

37. Kayagaki N, Wong MT, Stowe IB, Ramani SR, Gonzalez LC, Akashi-Takamura $S$, et al. Noncanonical inflammasome activation by intracellular LPS independent of TLR4. Science. 2013;341:1246-9.

38. Shi J, Zhao Y, Wang K, Shi X, Wang Y, Huang H, et al. Cleavage of GSDMD by inflammatory caspases determines pyroptotic cell death. Nature. 2015;526:660-5.

39. Kang TB, Yang SH, Toth B, Kovalenko A, Wallach D. Caspase8 blocks kinase RIPK3-mediated activation of the NLRP3 inflammasome. Immunity. 2012;38:27-40.

40. Lawlor KE, Khan N, Mildenhall A, Gerlic M, Croker BA, D'Cruz AA, et al. RIPK3 promotes cell death and NLRP3 inflammasome activation in the absence of MLKL. Nat Commun. 2015;6:6282.

41. Vince JE, Silke J. The intersection of cell death and inflammasome activation. Cell Mol Life Sci. 2016;73:2349-67.

42. Conos SA, Chen KW, De Nardo D, Hara H, Whitehead L, Nunez G, et al. Active MLKL triggers the NLRP3 inflammasome in a cell-intrinsic manner. Proc Natl Acad Sci USA. 2017;114:E961-e969.

43. Wang Y, Gao W, Shi X, Ding J, Liu W, He H, et al. Chemotherapy drugs induce pyroptosis through caspase-3 cleavage of a gasdermin. Nature. 2017;547:99-103.

44. Stockwell BR, Friedmann Angeli JP, Bayir H, Bush AI, Conrad M, Dixon SJ, et al. Ferroptosis: a regulated cell death nexus 
linking metabolism, redox biology, and disease. Cell. 2017;171:273-85.

45. Yagoda N, von RM, Zaganjor E, Bauer AJ, Yang WS, Fridman DJ, et al. RAS-RAF-MEK-dependent oxidative cell death involving voltage-dependent anion channels. Nature. 2007;447:864-8.

46. Dixon SJ, Lemberg KM, Lamprecht MR, Skouta R, Zaitsev EM, Gleason CE, et al. Ferroptosis: an iron-dependent form of nonapoptotic cell death. Cell. 2012;149:1060-72.

47. Dixon SJ, Stockwell BR. The role of iron and reactive oxygen species in cell death. Nat Chem Biol. 2013;10:9-17.

48. Friedmann Angeli JP, Schneider M, Proneth B, Tyurina YY, Tyurin VA, Hammond VJ, et al. Inactivation of the ferroptosis regulator Gpx4 triggers acute renal failure in mice. Nat Cell Biol. 2014;16:1180-91.

49. Linkermann A, Skouta R, Himmerkus N, Mulay SR, Dewitz C, De Zen F, et al. Synchronized renal tubular cell death involves ferroptosis. Proc Natl Acad Sci USA. 2014;111:16836-41.

50. Ingold I, Berndt C, Schmitt S, Doll S, Poschmann G, Buday K, et al. Selenium utilization by GPX4 Is required to prevent hydroperoxide-induced ferroptosis. Cell. 2018;172:409-422. e421.

51. Yang WS, Kim KJ, Gaschler MM, Patel M, Shchepinov MS, Stockwell BR. Peroxidation of polyunsaturated fatty acids by lipoxygenases drives ferroptosis. Proc Natl Acad Sci USA. 2016;113:E4966-E4975.

52. Seiler A, Schneider M, Forster H, Roth S, Wirth EK, Culmsee C, et al. Glutathione peroxidase 4 senses and translates oxidative stress into 12/15-lipoxygenase dependent- and AIF-mediated cell death. Cell Metab. 2008;8:237-48.

53. Ye LF, Stockwell BR. Transforming lipoxygenases: PE-specific enzymes in disguise. Cell. 2017;171:501-2.

54. Wenzel SE, Tyurina YY, Zhao J, St Croix CM, Dar HH, Mao G, et al. PEBP1 wardens ferroptosis by enabling lipoxygenase generation of lipid death signals. Cell. 2017;171:628-641.e626.

55. Friedmann Angeli JP, Conrad M. Lipoxygenases-killers against their will? ACS Cent Sci. 2018;4:312-4.

56. Shah R, Shchepinov MS, Pratt DA. Resolving the role of lipoxygenases in the initiation and execution of ferroptosis. ACS Cent Sci. 2018;4:387-96.

57. Shimada K, Hayano M, Pagano NC, Stockwell BR. Cell-line selectivity improves the predictive power of pharmacogenomic analyses and helps identify NADPH as biomarker for ferroptosis sensitivity. Cell Chem Biol. 2016;23:225-35.

58. Tonnus W, Linkermann A. "Death is my Heir"-ferroptosis connects cancer pharmacogenomics and ischemia-reperfusion injury. Cell Chem Biol. 2016;23:202-3.

59. Linkermann A. Nonapoptotic cell death in acute kidney injury and transplantation. Kidney Int. 2016;89:46-57.

60. Martin-Sanchez D, Ruiz-Andres O, Poveda J, Carrasco S, Cannata-Ortiz P, Sanchez-Nino MD, et al. Ferroptosis, but not necroptosis, is important in nephrotoxic folic acid-induced AKI. J Am Soc Nephrol. 2016;28:218-29.

61. Zilka O, Shah R, Li B, Friedmann Angeli JP, Griesser M, Conrad $\mathrm{M}$, et al. On the mechanism of cytoprotection by ferrostatin-1 and liproxstatin- 1 and the role of lipid peroxidation in ferroptotic cell death. ACS Cent Sci. 2017;3:232-43.

62. Yang WS, Stockwell BR. Synthetic lethal screening identifies compounds activating iron-dependent, nonapoptotic cell death in oncogenic-RAS-harboring cancer cells. Chem Biol. 2008;15:234-45.

63. Gaschler MM, Andia AA, Liu H, Csuka JM, Hurlocker B, Vaiana $\mathrm{CA}$, et al. FINO2 initiates ferroptosis through GPX4 inactivation and iron oxidation. Nat Chem Biol. 2018;14:507-15.

64. Shimada K, Skouta R, Kaplan A, Yang WS, Hayano M, Dixon $\mathrm{SJ}$, et al. Global survey of cell death mechanisms reveals metabolic regulation of ferroptosis. Nat Chem Biol. 2016;12:497-503.

65. Vandevoorde V, Haegeman G, Fiers W. Tumor necrosis factorinduced interleukin-6 expression and cytotoxicity follow a common signal transduction pathway in L929 cells. Biochem Biophys Res Commun. 1991;178:993-1001.

66. Vanden Berghe T, Demon D, Bogaert P, Vandendriessche B, Goethals A, Depuydt B, et al. Simultaneous targeting of IL-1 and IL-18 is required for protection against inflammatory and septic shock. Am J Respir Crit Care Med. 2014;189:282-91.

67. Kayagaki N, Stowe IB, Lee BL, O'Rourke K, Anderson K, Warming $\mathrm{S}$, et al. Caspase-11 cleaves gasdermin D for noncanonical inflammasome signalling. Nature. 2015;526:666-71.

68. Rickard JA, O'Donnell JA, Evans JM, Lalaoui N, Poh AR, Rogers T, et al. RIPK1 regulates RIPK3-MLKL-driven systemic inflammation and emergency hematopoiesis. Cell. 2014;157:1175-88.

69. Seifert L, Werba G, Tiwari S, Giao Ly NN, Alothman S, Alqunaibit $\mathrm{D}$, et al. The necrosome promotes pancreatic oncogenesis via CXCL1 and Mincle-induced immune suppression. Nature. 2016;532:245-9.

70. Kearney CJ, Cullen SP, Tynan GA, Henry CM, Clancy D, Lavelle EC, et al. Necroptosis suppresses inflammation via termination of TNF- or LPS-induced cytokine and chemokine production. Cell death Differ. 2015;22:1313-27.

71. Aachoui Y, Leaf IA, Hagar JA, Fontana MF, Campos CG, Zak DE, et al. Caspase- 11 protects against bacteria that escape the vacuole. Science. 2013;339:975-8.

72. Fernandes-Alnemri T, Wu J, Yu JW, Datta P, Miller B, Jankowski W, et al. The pyroptosome: a supramolecular assembly of ASC dimers mediating inflammatory cell death via caspase-1 activation. Cell Death Differ. 2007;14:1590-604.

73. Martinez J, Cunha LD, Park S, Yang M, Lu Q, Orchard R, et al. Noncanonical autophagy inhibits the autoinflammatory, lupuslike response to dying cells. Nature. 2016;533:115-9.

74. Zaman MK, White DA. Serum lactate dehydrogenase levels and Pneumocystis carinii pneumonia. Diagnostic and prognostic significance. Am Rev Respir Dis. 1988;137:796-800.

75. Kanczkowski W, Sue M, Bornstein SR. The adrenal gland microenvironment in health, disease and during regeneration. Hormones. 2017;16:251-65.

76. Kanczkowski W, Sue M, Zacharowski K, Reincke M, Bornstein SR. The role of adrenal gland microenvironment in the HPA axis function and dysfunction during sepsis. Mol Cell Endocrinol. 2015;408:241-8.

77. Jennewein C, Tran N, Kanczkowski W, Heerdegen L, Kantharajah A, Drose S, et al. Mortality of septic mice strongly correlates with adrenal gland inflammation. Crit Care Med. 2016;44: e190-199.

78. Bornstein SR. Predisposing factors for adrenal insufficiency. New Engl J Med. 2009;360:2328-39.

79. Wolkersdorfer GW, Marx C, Brown J, Schroder S, Fussel M, Rieber EP, et al. Prevalence of HLA-DRB1 genotype and altered Fas/Fas ligand expression in adrenocortical carcinoma. J Clin Endocrinol Metab. 2005;90:1768-74.

80. Bornstein SR, Ziegler CG, Krug AW, Kanczkowski W, Rettori $\mathrm{V}$, McCann SM, et al. The role of toll-like receptors in the immune-adrenal crosstalk. Ann N Y Acad Sci. 2006;1088:307-18

81. Altieri B, Sbiera S, Della Casa S, Weigand I, Wild V, Steinhauer $\mathrm{S}$, et al. Livin/BIRC7 expression as malignancy marker in adrenocortical tumors. Oncotarget. 2017;8:9323-38.

82. Batisse-Lignier M, Sahut-Barnola I, Tissier F, Dumontet T, Mathieu M, Drelon C, et al. P53/Rb inhibition induces metastatic adrenocortical carcinomas in a preclinical transgenic model. Oncogene. 2017;36:4445-56. 
83. Linkermann A, Stockwell BR, Krautwald S, Anders HJ. Regulated cell death and inflammation: an auto-amplification loop causes organ failure. Nat Rev Immunol. 2014;14:759-67.

84. Mulay SR, Linkermann A, Anders HJ. Necroinflammation in kidney disease. J Am Soc Nephrol. 2016;27:27-39.

85. Doi K, Rabb H. Impact of acute kidney injury on distant organ function: recent findings and potential therapeutic targets. Kidney Int. 2016;89:555-64.

86. Grigoryev DN, Liu M, Hassoun HT, Cheadle C, Barnes KC, $\mathrm{Rabb} \mathrm{H}$. The local and systemic inflammatory transcriptome after acute kidney injury. J Am Soc Nephrol. 2008;19:547-58.

87. Hassoun HT, Grigoryev DN, Lie ML, Liu M, Cheadle C, Tuder $\mathrm{RM}$, et al. Ischemic acute kidney injury induces a distant organ functional and genomic response distinguishable from bilateral nephrectomy. Am J Physiol Ren Physiol. 2007;293:F30-40.

88. Zhao H, Ning J, Lemaire A, Koumpa FS, Sun JJ, Fung A, et al. Necroptosis and parthanatos are involved in remote lung injury after receiving ischemic renal allografts in rats. Kidney Int. 2015;87:738-48.

89. Garg JP, Vucic D. Targeting cell death pathways for therapeutic intervention in kidney diseases. Semin Nephrol. 2016;36:153-61.

90. Linkermann A, Brasen JH, Himmerkus N, Liu S, Huber TB, Kunzendorf U, et al. Rip1 (receptor-interacting protein kinase 1) mediates necroptosis and contributes to renal ischemia/reperfusion injury. Kidney Int. 2012;81:751-61.

91. Skouta R, Dixon SJ, Wang J, Dunn DE, Orman M, Shimada K, et al. Ferrostatins inhibit oxidative lipid damage and cell death in diverse disease models. J Am Chem Soc. 2014;136:4551-6.

92. Martin-Sanchez D, Ruiz-Andres O, Poveda J, Carrasco S, Cannata-Ortiz P, Sanchez-Nino MD, et al. Ferroptosis, but not necroptosis, is important in nephrotoxic folic acid-induced AKI. J Am Soc Nephrol. 2017;28:218-29.

93. Martin-Sanchez D, Fontecha-Barriuso M, Carrasco S, SanchezNino MD, Massenhausen AV, Linkermann A, et al. TWEAK and RIPK1 mediate a second wave of cell death during AKI. Proc Natl Acad Sci USA. 2018;115:4182-7.

94. Schreiber A, Rousselle A, Becker JU, von Massenhausen A, Linkermann A, Kettritz R. Necroptosis controls NET generation and mediates complement activation, endothelial damage, and autoimmune vasculitis. Proc Natl Acad Sci USA. 2017;114: E9618-e9625.

95. Basu N, McClean A, Harper L, Amft EN, Dhaun N, Luqmani RA, et al. Explaining fatigue in ANCA-associated vasculitis. Rheumatology. 2013;52:1680-5.

96. Brodie D, Bacchetta M. Extracorporeal membrane oxygenation for ARDS in adults. New Engl J Med. 2011;365:1905-14.

97. Lorenz G, Schmalenberg M, Kemmner S, Haller B, Steubl D, Pham $\mathrm{D}$, et al. Mortality prediction in stable hemodialysis patients is refined by YKL-40, a 40-kDa glycoprotein associated with inflammation. Kidney Int. 2018;93:221-30.

98. Pupim LB, Himmelfarb J, McMonagle E, Shyr Y, Ikizler TA. Influence of initiation of maintenance hemodialysis on biomarkers of inflammation and oxidative stress. Kidney Int. 2004:65:2371-9.

99. Sklar AH, Beezhold DH, Newman N, Hendrickson T, Dreisbach AW. Postdialysis fatigue: lack of effect of a biocompatible membrane. Am J Kidney Dis. 1998;31:1007-10.

100. Kollef MH, Schuster DP. The acute respiratory distress syndrome. New Engl J Med. 1995;332:27-37.

101. Fan EKY, Fan J. Regulation of alveolar macrophage death in acute lung inflammation. Respir Res. 2018;19:50.

102. Reiss LK, Schuppert A, Uhlig S. Inflammatory processes during acute respiratory distress syndrome: a complex system. Curr Opin Crit care. 2018;24:1-9.
103. Quilez ME, Lopez-Aguilar J, Blanch L. Organ crosstalk during acute lung injury, acute respiratory distress syndrome, and mechanical ventilation. Curr Opin Crit care. 2012;18:23-28.

104. Williams AE, Chambers RC. The mercurial nature of neutrophils: still an enigma in ARDS? Am J Physiol Lung Cell Mol Physiol. 2014;306:L217-230.

105. Desai J, Kumar SV, Mulay SR, Konrad L, Romoli S, Schauer C, et al. PMA and crystal-induced neutrophil extracellular trap formation involves RIPK1-RIPK3-MLKL signaling. Eur J Immunol. 2016;46:223-9.

106. Annane D, Renault A, Brun-Buisson C, Megarbane B, Quenot JP, Siami S, et al. Hydrocortisone plus fludrocortisone for adults with septic shock. New Engl J Med. 2018;378:809-18.

107. Venkatesh B, Finfer S, Cohen J, Rajbhandari D, Arabi Y, Bellomo R, et al. Adjunctive glucocorticoid therapy in patients with septic shock. New Engl J Med. 2018;378:797-808.

108. Upton JW, Kaiser WJ, Mocarski ES. DAI/ZBP1/DLM-1 complexes with RIP3 to mediate virus-induced programmed necrosis that is targeted by murine cytomegalovirus vIRA. Cell Host Microbe. 2012;11:290-7.

109. Cho YS, Challa S, Moquin D, Genga R, Ray TD, Guildford M, et al. Phosphorylation-driven assembly of the RIP1-RIP3 complex regulates programmed necrosis and virus-induced inflammation. Cell. 2009;137:1112-23.

110. Moriwaki K, Chan FK. RIP3: a molecular switch for necrosis and inflammation. Genes Dev. 2013;27:1640-9.

111. Thapa RJ, Nogusa S, Chen P, Maki JL, Lerro A, Andrake M, et al. Interferon-induced RIP1/RIP3-mediated necrosis requires PKR and is licensed by FADD and caspases. Proc Natl Acad Sci USA. 2013;110:E3109-18.

112. von Massenhausen A, Tonnus W, Himmerkus N, Parmentier S, Saleh D, Rodriguez D, et al. Phenytoin inhibits necroptosis. Cell death Dis. 2018;9:359.

113. Ofengeim D, Mazzitelli S, Ito Y, DeWitt JP, Mifflin L, Zou C, et al. RIPK1 mediates a disease-associated microglial response in Alzheimer's disease. Proc Natl Acad Sci USA. 2017;114: E8788-e8797.

114. Ito Y, Ofengeim D, Najafov A, Das S, Saberi S, Li Y, et al. RIPK1 mediates axonal degeneration by promoting inflammation and necroptosis in ALS. Science. 2016;353:603-8.

115. Brandtzaeg $P$, van Deuren M. Classification and pathogenesis of meningococcal infections. Methods Mol Biol. 2012;799:21-35.

116. Tuo QZ, Lei P, Jackman KA, Li XL, Xiong H, Li XL, et al. Taumediated iron export prevents ferroptotic damage after ischemic stroke. Mol Psychiatry. 2017;22:1520-30.

117. Carlson BA, Tobe R, Yefremova E, Tsuji PA, Hoffmann VJ, Schweizer U, et al. Glutathione peroxidase 4 and vitamin $\mathrm{E}$ cooperatively prevent hepatocellular degeneration. Redox Biol. 2016;9:22-31.

118. Newton K, Dugger DL, Maltzman A, Greve JM, Hedehus M, Martin-McNulty B, et al. RIPK3 deficiency or catalytically inactive RIPK1 provides greater benefit than MLKL deficiency in mouse models of inflammation and tissue injury. Cell Death Differ. 2016;23:1565-76.

119. Lador A, Hasdai D, Mager A, Porter A, Goldenberg I, Shlomo $\mathrm{N}$, et al. Incidence and prognosis of pericarditis after st-elevation myocardial infarction (from the acute coronary syndrome Israeli Survey 2000 to 2013 registry database). Am J Cardiol. 2018;121:690-4.

120. Samtleben W, Mistry-Burchardi N, Hartmann B, Lennertz A, Bosch T. Therapeutic plasma exchange in the intensive care setting. Ther Apher. 2001;5:351-7.

121. Luedde T, Kaplowitz N, Schwabe RF. Cell death and cell death responses in liver disease: mechanisms and clinical relevance. Gastroenterology. 2014;147:765-783.e764. 
122. Dara L, Liu ZX, Kaplowitz N. Questions and controversies: the role of necroptosis in liver disease. Cell death Discov. 2016;2:16089.

123. Sanz AB, Ruiz-Andres O, Sanchez-Nino MD, Ruiz-Ortega M, Ramos AM, Ortiz A. Out of the TWEAKlight: elucidating the role of Fn14 and TWEAK in acute kidney injury. Semin Nephrol. 2016;36:189-98.

124. Martens S, Jeong M, Tonnus W, Feldmann F, Hofmans S, Goossens V, et al. Sorafenib tosylate inhibits directly necrosome complex formation and protects in mouse models of inflammation and tissue injury. Cell Death Dis. 2017;8:e2904.

125. Kers J, Leemans JC, Linkermann A.An overview of pathways of regulated necrosis in acute kidney injury. Semin Nephrol. 2016;36:139-52.

126. Lau A, Wang S, Jiang J, Haig A, Pavlosky A, Linkermann A, et al. RIPK3-mediated necroptosis promotes donor kidney inflammatory injury and reduces allograft survival. Am J Transplant. 2013;13:2805-18.

127. Linkermann A, Hackl MJ, Kunzendorf U, Walczak H, Krautwald S, Jevnikar AM. Necroptosis in immunity and ischemiareperfusion injury. Am J Transplant. 2013;13:2797-804.

128. Sarhan M, von Massenhausen A, Hugo C, Oberbauer R, Linkermann A. Immunological consequences of kidney cell death. Cell Death Dis. 2018;9:114.

129. Kox J, Moers C, Monbaliu D, Strelniece A, Treckmann J, Jochmans I, et al. The benefits of hypothermic machine preservation and short cold ischemia times in deceased donor kidneys. Transplantation. 2018;102:1344-50.

130. Balyura M, Gelfgat E, Ehrhart-Bornstein M, Ludwig B, Gendler $\mathrm{Z}$, Barkai U, et al. Transplantation of bovine adrenocortical cells encapsulated in alginate. Proc Natl Acad Sci USA. 2015;112:2527-32.

131. Balyura M, Gelfgat E, Steenblock C, Androutsellis-Theotokis A, Ruiz-Babot G, Guasti L, et al. Expression of progenitor markers is associated with the functionality of a bioartificial adrenal cortex. PloS One. 2018;13:e0194643.

132. Pan L, Yao DC, Yu YZ, Chen BJ, Li SJ, Hu GH, et al. Activation of necroptosis in a rat model of acute respiratory distress syndrome induced by oleic acid. Sheng li xue bao: [Acta Physiol Sin]. 2016;68:661-8.

133. Pan L, Yao DC, Yu YZ, Li SJ, Chen BJ, Hu GH, et al. Necrostatin-1 protects against oleic acid-induced acute respiratory distress syndrome in rats. Biochem Biophys Res Commun. 2016;478:1602-8.

134. Qing DY, Conegliano D, Shashaty MG, Seo J, Reilly JP, Worthen GS, et al. Red blood cells induce necroptosis of lung endothelial cells and increase susceptibility to lung inflammation. Am J Respir Crit Care Med. 2014;190:1243-54.

135. Wang L, Wang T, Li H, Liu Q, Zhang Z, Xie W, et al. Receptor interacting protein 3-mediated necroptosis promotes lipopolysaccharide-induced inflammation and acute respiratory distress syndrome in mice. PloS One. 2016;11:e0155723.

136. Vanden Berghe $\mathrm{T}$, Linkermann A. Take my breath away: necrosis in kidney transplants kills the lungs! Kidney Int. 2015;87:680-2.

137. Sanz AB, Izquierdo MC, Sanchez-Nino MD, Ucero AC, Egido J, Ruiz-Ortega M, et al. TWEAK and the progression of renal disease: clinical translation. Nephrol Dial Transplant. 2014;29 (Suppl 1):i54-i62.

138. Ekaney ML, Otto GP, Sossdorf M, Sponholz C, Boehringer M, Loesche W, et al. Impact of plasma histones in human sepsis and their contribution to cellular injury and inflammation. Crit Care. 2014;18:543.

139. Tejera P, Meyer NJ, Chen F, Feng R, Zhao Y, O'Mahony DS, et al. Distinct and replicable genetic risk factors for acute respiratory distress syndrome of pulmonary or extrapulmonary origin. J Med Genet. 2012;49:671-80.

140. Xu W, Song Y. Biomarkers for patients with trauma associated acute respiratory distress syndrome. Mil Med Res. 2017;4:25.

141. Zedler S, Faist E. The impact of endogenous triggers on traumaassociated inflammation. Curr Opin Crit Care. 2006;12:595-601.

142. Kitur K, Wachtel S, Brown A, Wickersham M, Paulino F, Penaloza HF, et al. Necroptosis promotes Staphylococcus aureus clearance by inhibiting excessive inflammatory signaling. Cell Rep. 2016;16:2219-30.

143. Shutinoski B, Alturki NA, Rijal D, Bertin J, Gough PJ, Schlossmacher MG, et al. K45A mutation of RIPK1 results in poor necroptosis and cytokine signaling in macrophages, which impacts inflammatory responses in vivo. Cell Death Differ. 2016;23:1628-37.

144. Vasconcellos LR, Dutra FF, Siqueira MS, Paula-Neto HA, Dahan J, Kiarely E, et al. Protein aggregation as a cellular response to oxidative stress induced by heme and iron. Proc Natl Acad Sci USA. 2016;113:E7474-e7482.

145. Wang B, Li J, Gao HM, Xing YH, Lin Z, Li HJ, et al. Necroptosis regulated proteins expression is an early prognostic biomarker in patient with sepsis: a prospective observational study. Oncotarget. 2017;8:84066-73.

146. Duprez L, Takahashi N, Van HF, Vandendriessche B, Goossens $\mathrm{V}$, Vanden Berghe T, et al. RIP kinase-dependent necrosis drives lethal systemic inflammatory response syndrome. Immunity. 2011;35:908-18.

147. Linkermann A, Brasen JH, De Zen F, Weinlich R, Schwendener RA, Green DR, et al. Dichotomy between RIP1- and RIP3mediated necroptosis in tumor necrosis factor-alpha-induced shock. Mol Med. 2012;18:577-86.

148. Qu Y, Misaghi S, Newton K, Maltzman A, Izrael-Tomasevic A, Arnott D, et al. NLRP3 recruitment by NLRC4 during salmonella infection. J Exp Med. 2016;213:877-85.

149. Thurston TL, Matthews SA, Jennings E, Alix E, Shao F, Shenoy AR, et al. Growth inhibition of cytosolic Salmonella by caspase1 and caspase-11 precedes host cell death. Nat Commun. 2016;7:13292.

150. Broz P, Ruby T, Belhocine K, Bouley DM, Kayagaki N, Dixit VM, et al. Caspase-11 increases susceptibility to salmonella infection in the absence of caspase-1. Nature. 2012;490: 288-91.

151. Kayagaki N, Stowe IB, Lee BL, O'Rourke K, Anderson K, Warming $\mathrm{S}$, et al. Caspase-11 cleaves gasdermin $\mathrm{D}$ for noncanonical inflammasome signaling. Nature 2015;526;666-67.

152. Huebener P, Pradere JP, Hernandez C, Gwak GY, Caviglia JM, $\mathrm{Mu} \mathrm{X}$, et al. The HMGB1/RAGE axis triggers neutrophilmediated injury amplification following necrosis. J Clin Invest. 2015;125:539-50.

153. Muhl H. STAT3, a key parameter of cytokine-driven tissue protection during sterile inflammation - the case of experimental acetaminophen (paracetamol)-induced liver damage. Front Immunol. 2016;7:163.

154. Tadagavadi RK, Reeves WB. Endogenous IL-10 attenuates cisplatin nephrotoxicity: role of dendritic cells. J Immunol. 2010;185:4904-11.

155. Cooke JV, Whipple GH. Proteose intoxications and injury of body protein: IV. The metabolism of dogs with sterile abscess, pancreatitis, and pleuritis. J Exp Med. 1918;28:223-41.

156. Xu B, Jiang M, Chu Y, Wang W, Chen D, Li X, et al. Gasdermin D plays a key role as a pyroptosis executor of non-alcoholic steatohepatitis in humans and mice. J Hepatol 2017;68:773-782.

157. Allam R, Kumar SV, Darisipudi MN, Anders HJ. Extracellular histones in tissue injury and inflammation. $\mathrm{J}$ Mol Med. 2014;92:465-72. 
158. Ergin B, Zuurbier CJ, Kapucu A, Ince C. Divergent effects of hypertonic fluid resuscitation on renal pathophysiological and structural parameters in rat model of lower body ischemia/ reperfusion-induced sterile inflammation. Shock, Published ahead of print 2017.

159. Li L, Okusa MD. Macrophages, dendritic cells, and kidney ischemia-reperfusion injury. Semin Nephrol. 2010;30:268-77.

160. Spahn JH, Kreisel D. Monocytes in sterile inflammation: recruitment and functional consequences. Arch Immunol Et Ther Exp. 2014;62:187-94.

161. Yazdani HO, Chen HW, Tohme S, Tai S, van der Windt DJ, Loughran P, et al. IL-33 exacerbates liver sterile inflammation by amplifying neutrophil extracellular trap formation. J Hepatol. 2017;68:130-139.

162. Martinez J, Malireddi RK, Lu Q, Cunha LD, Pelletier S, Gingras S, et al. Molecular characterization of LC3associated phagocytosis reveals distinct roles for Rubicon, NOX2 and autophagy proteins. Nat Cell Biol. 2015;17:893-906.

163. Schumann-Bischoff A, Schmitz J, Scheffner I, Schmitt R, Broecker V, Haller H, et al. Distinct morphological features of acute tubular injury in renal allografts correlate with clinical outcome. Am J Physiol Ren Physiol 2018;315: F701-F710. 